\title{
Mamíferos carnívoros e sua relação com a diversidade de hábitats no Parque Nacional dos Aparados da Serra, sul do Brasil
}

\author{
Maria de Fátima M. dos Santos ${ }^{1}$, Mateus Pellanda ${ }^{1,2}$, Ana Cristina Tomazzoni1 ${ }^{1,2}$, \\ Heinrich Hasenack ${ }^{1} \&$ Sandra Maria Hartz ${ }^{1}$

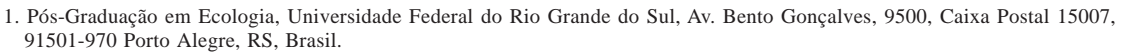
91501-970 Porto Alegre, RS, Brasil. \\ 2. Bolsista de Iniciação Científica PROPESQ/UFRGS.
}

\begin{abstract}
Carnivore mammals and their relation with habitat diversity in Aparados da Serra National Park, southern Brazil. A survey of carnivore mammals was accomplished in Aparados da Serra National Park from February 1998 to March 2000. The park has 10,250 ha and is considered a biodiversity core area of the Atlantic Forest Biosphere Reserve in the Rio Grande do Sul State, Brazil. The landscape is characterized by relatively well preserved relicts of Araucaria angustifolia (Bertol.) Kuntze forest, grasslands and Atlantic Forest, which have contributed for the survival of endangered carnivore mammals. The National Park was divided in a grid of $16 \mathrm{~km}^{2}$ cells using a 1:50,000 scale map. The animals were recorded using indirect methods, by identifying signs (scats, tracks) and direct observation in $2.5 \mathrm{~km}$ long and $5 \mathrm{~m}$ wide transects, with 10 replicates in each grid cell. Interviews with local people were also used to confirm the animal presence. A total of 13 species was recorded: Procyon cancrivorus (Cuvier, 1798), Pseudalopex gymnocercus (G. Fischer, 1814), Leopardus pardalis (Linnaeus, 1758) and Cerdocyon thous (Linnaeus, 1766) were the most frequent species registered. Nasua nasua (Linnaeus 1766), Herpailurus yaguarondi (Lacépède, 1809), Chrysocyon brachyurus (Illiger, 1815), Eira barbara (Linnaeus, 1758), Leopardus sp., Puma concolor (Linnaeus, 1771), Galictis cuja (Molina, 1782), Conepatus chinga (Molina, 1892) and Lontra longicaudis (Olfers, 1818) showed lower frequencies. The Park presented areas with significant differences (Mantel Test, $\mathrm{P}<0.05)$ in species richness and composition related to habitat classes. Areas with high habitat richness presented high species richness. The Araucaria forest was the habitat that presented the higher carnivore richness. The border areas of the Park are influenced by several environmental degradation factors that could be affecting the distribution of carnivores.
\end{abstract}

KEYWORDS. Neotropical Mammals, Carnivora, Aparados da Serra, Atlantic Forest.

\section{INTRODUÇÃO}

No Rio Grande do Sul (RS), a Floresta Ombrófila Densa, Mata Atlântica sensu stricto, encontra seu limite meridional. Tal posição geográfica proporciona o contato com ecossistemas associados, como a Floresta Estacional Semi-decidual, a mata com araucária (Floresta Ombrófila Mista) e os Campos de Cima da Serra. A região do Planalto mantém áreas preservadas devido ao difícil acesso ocasionado pelo relevo acidentado, estabelecendo uma estreita relação com a Mata Atlântica, que cobre as encostas da Serra Geral, compartilhando muitas espécies animais e vegetais (GUADAGNIN et al., 1998).

Conforme o IBGE (1986), a cobertura de mata com araucária e Campos de Cima da Serra no RS é de 36.023 $\mathrm{km}^{2}$, dos quais $926,79 \mathrm{~km}^{2}$ são áreas protegidas do Planalto que representam 2,5\% dos ambientes citados. Embora sujeitas aos impactos da expansão humana, promotora da destruição e fragmentação de hábitats naturais, estas áreas ainda apresentam manchas de vegetação com maciços florestais de matas primárias e secundárias, constituindo um corredor na própria região do Planalto, conectado à região central do Estado (GuADAGNin et al., 1998).

Estabelecidas no Planalto, unidades de conservação como o Parque Nacional dos Aparados da Serra (PNAS) e o Parque Nacional da Serra Geral contribuem com $29,72 \%$ do total de áreas protegidas do RS (Marcuzzo et al., 1998). Por apresentarem remanescentes de formações naturais, garantem a preservação de uma parcela do corredor mencionado, tornando-se importantes refúgios mantenedores da riqueza faunística da região.

Dentre a mastofauna, os carnívoros são importantes componentes ecológicos dos ecossistemas, controlando as populações de suas presas, influenciando os processos de dispersão de sementes e a diversidade da comunidade (Terborgh, 1992). Segundo Terborgh $e t$ al. (1999), os grandes carnívoros têm um papel importante na regulação dos ecossistemas, sendo considerados como espécies-chave por manter e restaurar a diversidade e a resiliência dos mesmos. Assegurando-se a manutenção das populações de grandes carnívoros, protegem-se outras espécies de um mesmo ecossistema (SOUlé \& TERBORGH, 1999).

Segundo a lista da mastofauna do Plano de Manejo do PNAS, elaborada por Breyer, 1978 apud IBDF (1982), ocorreriam no parque os seguintes carnívoros: mãopelada, Procyon cancrivorus (Cuvier, 1798); quati, Nasua nasua (Linnaeus 1766); graxaim-do-campo, Pseudalopex gymnocercus (G. Fischer, 1814); graxaim-do-mato, Cerdocyon thous (Linnaeus, 1766); lobo-guará, Chrysocyon brachyurus (Illiger, 1815); jaguatirica, Leopardus pardalis (Linnaeus, 1758); gato-mourisco, Herpailurus yaguarondi (Lacépède, 1809); gatomaracajá, Leopardus wiedii (Schinz, 1821); gato-do-matopequeno, L. tigrinus (Schreber, 1775); leão-baio, Puma concolor (Linnaeus, 1771); irara, Eira barbara (Linnaeus, 
1758); furão-pequeno, Galictis cuja (Molina, 1782); furão, G. vittata (Schreber, 1776); cangambá, Conepatus semistriatus (Boddaert, 1785); zorrilho, C. chinga (Molina, 1782) e ariranha, Pteronura brasiliensis (Gmelin, 1788). Esta lista possui cerca de 20 anos, sendo obtida por apanhados bibliográficos, não existindo nenhum trabalho publicado com levantamentos a campo sobre a situação dos carnívoros da área. É necessário atualizar informações sobre o grupo, o que poderá fornecer dados para a detecção de possíveis mudanças na composição da fauna silvestre do Parque, que podem estar relacionadas com o grau de conservação do seu contexto.

O objetivo é registrar e mapear as ocorrências das espécies de carnívoros existentes no PNAS, relacionando a riqueza de animais averiguada em diferentes locais do Parque com a diversidade de hábitats representada pela cobertura e uso do solo.

\section{MATERIAL E MÉTODOS}

O Parque Nacional dos Aparados da Serra, administrado pelo Instituto Brasileiro do Meio Ambiente e Recursos Naturais Renováveis (IBAMA), localiza-se na porção noroeste do RS, abrangendo os campos e borda do planalto. Seu limite político inclui o município de Cambará do Sul, as encostas do Planalto e, na porção sudoeste de Santa Catarina, o município de Praia Grande. Criado em 1959, o Parque possui área de 10.250 ha (29¹0’00"S; 5005’00”'W), situando-se na área-núcleo da Reserva da Biosfera da Mata Atlântica e Ecossistemas Associados, contíguo ao Parque Nacional da Serra Geral (fig. 1). Sua paisagem apresenta basicamente sete formações vegetais: campos (limpos, turfosos ou muito

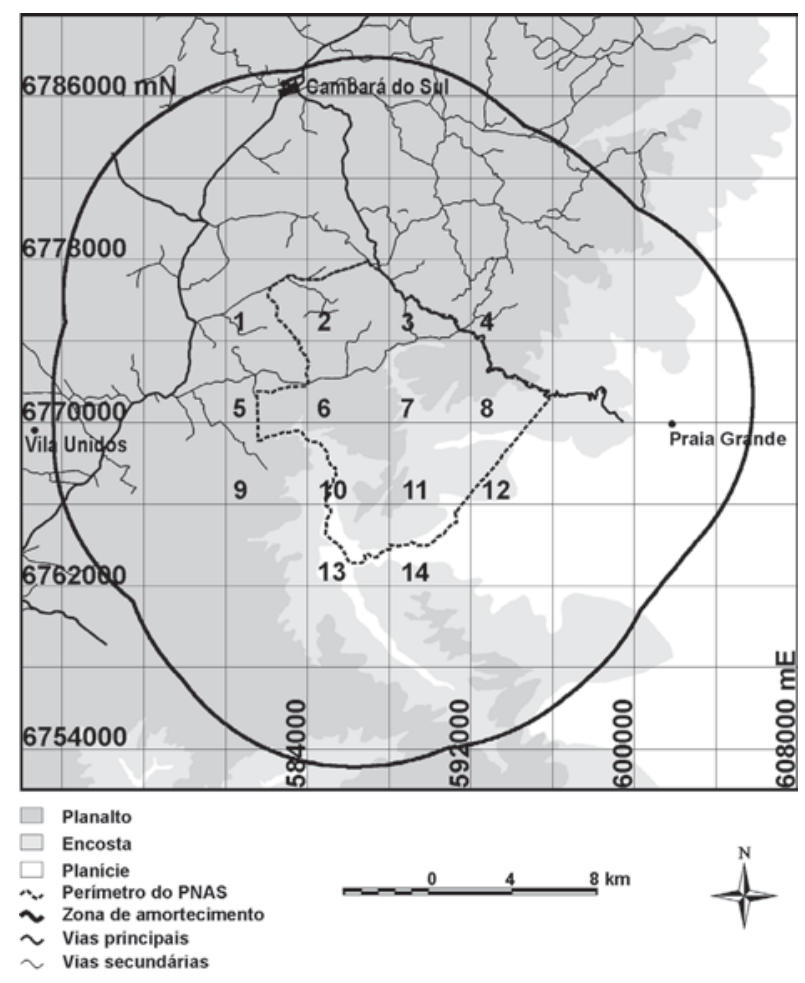

Fig. 1. Parque Nacional dos Aparados da Serra, sul do Brasil, com a delimitação das unidades amostrais (números 1 - 14). Coordenadas geográficas em UTM, zona 22. úmidos) com formas herbáceas e arbustivas; mata com araucária, predominando no seu estrato superior a Araucaria angustifolia (Bertol.) Kuntze, o pinheirobravo, Podocarpus lambertii Klotzsch ex Endl., a cascade-anta (Drimys sp.) e muitas mirtáceas, como a goiabeirada-serra, Feijoa sellowiana Berg; Floresta Atlântica, com palmiteiros, Euterpe edulis Martius, figueiras (Ficus sp.) e canelas (Ocotea sp. e Nectandra sp.); matinha nebular, com a corticeira-da-serra, Erythrina falcata Benth., quaresmeiras (melastomatáceas) e bracatingas (Mimosa sp.); vegetação rupreste junto às faces úmidas dos cânions do Itaimbezinho e Faxinal, com bromeliáceas e Gunnera manicata Lindm.; banhados e turfeiras (RAMBO, 1956).

O clima da região, com base em dados da estação meteorológica de Bom Jesus, é temperado, com 4 estações características. A temperatura média anual é de $14,7^{\circ} \mathrm{C}$, com mínima de $-5,8^{\circ} \mathrm{C}$ no inverno, podendo ocorrer precipitação de neve, e máxima de $20^{\circ} \mathrm{C}$ no verão (INMET, 1992). Os índices pluviométricos variam de 1500 a 1750 mm nas partes mais baixas e de 1750 a $2250 \mathrm{~mm}$ no planalto e encosta. Os nevoeiros são freqüentes o ano todo, devido à diferença de altitude entre o planalto e as baixadas e pela proximidade do litoral (IBDF, 1982).

A primeira etapa deste trabalho constituiu-se no levantamento dos mamíferos carnívoros existentes no local. Foi realizada no período de fevereiro a dezembro de 1998, contando com 61 dias de campo em 19 expedições de 3 dias em média. Fez-se a averiguação do local com mapas na escala 1:50.000 do Serviço Geográfico do Exército de 1979, bússola e GPS (Global Positioning System), visando o reconhecimento geográfico da área de estudo, geo-referenciamento das informações de uso do solo (áreas de lavoura, matas, solo descoberto), dos pontos de ocorrência dos animais e dos percursos realizados. Com estes instrumentos foram aferidos os dados obtidos para a definição do delineamento amostral deste trabalho, incluindo a localização segura dos pesquisadores em áreas remotas do PNAS.

O levantamento das espécies de carnívoros do PNAS foi efetuado em transecções fixas em faixas (RUDRAN et al., 1996) de $2,5 \mathrm{~km}$ extensão e com 2 a $5 \mathrm{~m}$ de largura percorridas em caminhadas, a cavalo e com carro para alguns percursos noturnos (fig. 2). Cerca de 30 transecções foram mensuradas utilizando-se passadas duplas e trena, o que auxiliou na aferição do tempo de recobrimento das mesmas, cuja marca foi estabelecida em aproximadamente uma transecção $(2,5 \mathrm{~km})$ a cada uma hora e meia. Foram amostrados nesta fase 19 percursos em 122 repetições, das quais 88 foram realizadas durante o dia e 34 à noite, sendo percorridos cerca de 47,5 km do local de estudo. Foi averiguada nos percursos a pé uma área de 178,75 ha. Dois percursos foram realizados a cavalo e 33 percursos noturnos com carro.

Os percursos realizados distribuíram-se em diferentes áreas do Parque na porção do Planalto, com orientação definida pelos pontos cardeais através do uso de bússola. Percorreram-se também trilhas antigas e estradas que cruzavam a região de estudo. As observações foram feitas no intervalo das 7 horas e 30 minutos até às 16 horas, e das 22 às 24 horas. As espécies foram registradas por três métodos: identificação de 


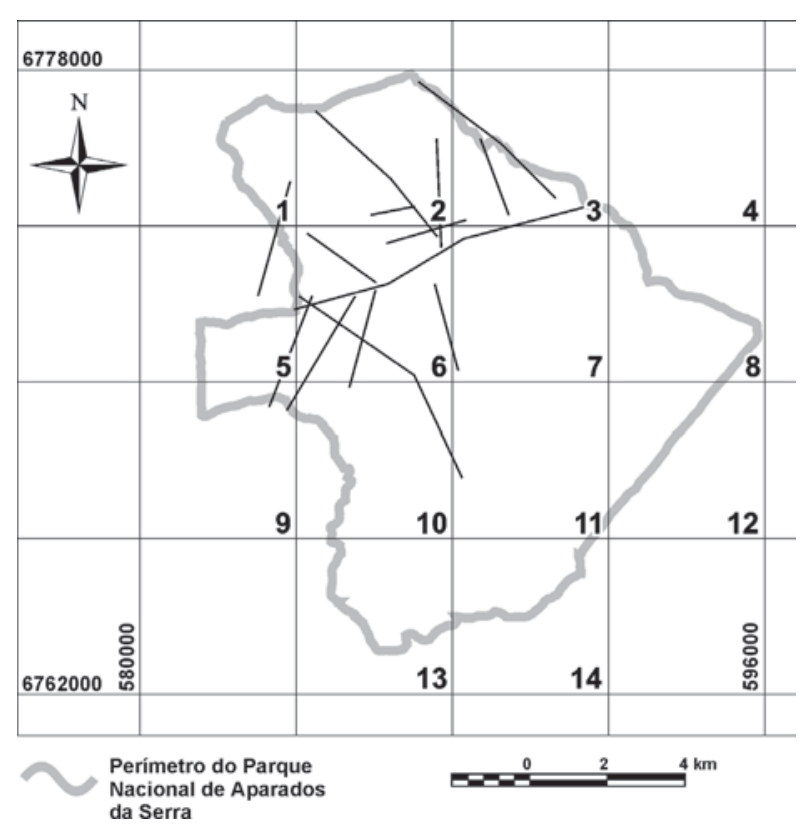

Fig. 2. Perímetro do Parque Nacional dos Aparados da Serra, indicando as transecções realizadas durante o período de fevereiro de 1998 a dezembro de 1998. Coordenadas geográficas em UTM, zona 22 .

vestígios, como pegadas, fezes, carcaças, registro de vocalizações e marcações (BECKER \& DALPONTE, 1991; SimonetTi \& Huareco, 1999); observações diretas e realização de breves entrevistas com funcionários do Parque (fiscais, administrador e vigias) e três famílias de moradores que ainda permaneciam vivendo no local. As entrevistas partiram da pergunta "Você tem visto animais com pêlos, selvagens ou do mato na sua propriedade ou arredores? Quais?". Em alguns casos solicitava-se ao entrevistado a descrição do animal e verificava-se se a descrição coincidia com fotografias que lhes eram apresentadas.

A segunda etapa deste trabalho compreendeu 120 dias de atividades a campo de março de 1999 a março de 2000. Delineou-se uma amostragem estratificada dividindo-se a área total do parque em 14 quadrículas de $16 \mathrm{~km}^{2}$ cada $(4 \mathrm{~km} \times 4 \mathrm{~km})$. Cada quadrícula foi considerada uma unidade amostral onde foram estabelecidas 10 repetições com transecções em faixas de $2,5 \mathrm{~km}$ de extensão e 2 a 5 metros de largura. Estas foram distribuídas conforme orientação cardinal, sendo sorteada a direção de partida com a bússola do primeiro percurso no início dos trabalhos em cada quadrícula.

Foram realizados 140 percursos (fig. 3), sendo averiguados $350 \mathrm{~km}$ e uma área de 437,5 ha, incluindo o interior dos cânions do Itaimbezinho e do Faxinal. A cada dia foram realizados, em média, quatro percursos. Cada unidade amostral foi averiguada de forma qualitativa quanto à presença ou ausência dos carnívoros. As espécies foram detectadas e determinadas principalmente pela identificação de seus vestígios e por observações visuais. A quadrícula foi dimensionada partindo do pressuposto que seria um recorte da paisagem do parque, contendo um mosaico de hábitats potencialmente utilizado pelos carnívoros detectados na primeira fase do trabalho. As quadrículas amostrariam assim, diferentes

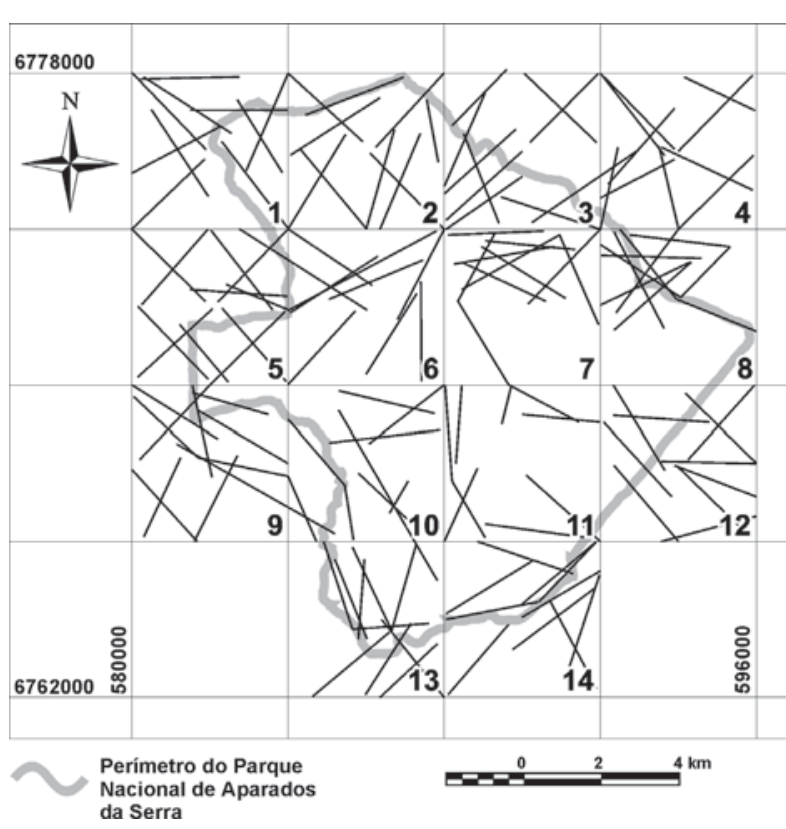

Fig. 3. Perímetro do Parque Nacional dos Aparados da Serra, indicando as transecções realizadas durante o período de março de 1999 a março de 2000. Coordenadas geográficas em UTM, zona 22 .

secções do local de estudo (planalto, encosta e planície), em uma escala cartográfica de fácil interpretação espacial (UTM, escalonada em metros no terreno). Considerouse também que sua área $\left(16 \mathrm{~km}^{2}\right)$ apresentava um valor intermediário quando comparada com os menores valores das áreas de vida citado na literatura para os maiores carnívoros registrados no local (DiETZ, 1984; LiNDZEY et al., 1994). Projetou-se a viabilidade de tempo de um pesquisador/hora averiguar em caminhadas a unidade amostral no período de realização desta segunda fase. Não foram contempladas observações sazonais devido à dificuldade de amostragem das quadrículas de forma simultânea para o mesmo período do ano.

As trilhas utilizadas e pontos de ocorrência dos animais foram registrados em protocolos de campo, sendo anotadas as informações do local de ocorrência, número da quadrícula, dimensões dos rastros e das fezes dos animais, sendo geo-referenciados com receptor GPS. Cada registro foi considerado como presença e utilização pelos animais (SMAllwood \& FitzhuGH, 1995) dos mosaicos de hábitats encontrados no Parque.

A divisão, o mapeamento e a quantificação de área dos diferentes padrões de cobertura do solo foram realizados utilizando-se o Sistema de Informações Geográficas (SIG) Idrisi, versão 3.2 para Windows (EASTMAN, 1999) e CartaLinx (Hagan, 1998). Os arquivos vetoriais foram registrados em mesa digitalizadora, tendo como base as folhas MI 2955/2 (Cambará do Sul), MI 2956/1 (Praia Grande) e MI 2955/4 (Aratinga), todas com escala de 1:50.000, de 1979. Para análise da cobertura vegetal foi utilizada a classificação não-supervisionada da imagem digital geo-referenciada, órbita 22080 quadrante C (resolução $30 \mathrm{~m}$ ), de 16 de março de 1997, do satélite Landsat TM 5, bandas 5, 4 e 3 .

A suficiência amostral, relativa ao número de percursos em cada unidade amostral, foi avaliada 
utilizando-se o programa Sampler (PILlaR, 1998). Uma análise de agrupamento (MANLY, 1994) foi realizada com a matriz de dados da composição qualitativa da presença/ ausência de carnívoros para as 14 quadrículas amostrais. Para tais análises, os algoritmos utilizados foram Distância Euclidiana para medida de semelhança e a Variância Mínima como método de agrupamento, utilizando-se o programa Multiv (PILLAR, 1997).

O teste de correlação de Mantel (MANLy, 1994) foi utilizado para verificar a associação entre as matrizes de dados de cobertura vegetal (mosaico de hábitats) e da composição das espécies. O teste foi baseado em uma medida de correlação entre duas matrizes de distância. Uma das matrizes de distância foi calculada a partir de dados de cobertura vegetal entre as 14 unidades amostrais (quadrículas). A outra matriz de distância, também entre as mesmas unidades amostrais, foi baseada nos dados de composição de espécies. A medida de correlação entre as matrizes foi o coeficiente de correlação de Pearson envolvendo 91 pares de elementos correspondentes das duas matrizes. O teste de Mantel gerou uma probabilidade (p) obtida através de 1000 iterações em que elementos das matrizes foram permutados aleatoriamente. A probabilidade obtida pelo teste permite testar a hipótese nula de não-associação entre as distâncias baseada na fauna e na cobertura vegetal.

\section{RESULTADOS}

Foram registradas, no PNAS, 13 espécies de carnívoros de quatro famílias com distribuição neotropical. As espécies são apresentadas, segundo a forma de registro (tab. I). Rastros e fezes foram os indícios mais frequientes da presença dos animais no local. Visualizações, relatos de funcionários do Parque e entrevistas complementaram as informações da ocorrência de algumas espécies na área. Pêlos de autolimpeza, encontrados em fezes coletadas, foram outro indício para a confirmação da presença das espécies.

Das 122 repetições dos percursos realizados na primeira etapa, 64 apresentaram vestígios. Destes, cerca de $50 \%$ apresentaram vestígios de Procyon cancrivorus, $37 \%$ de Pseudalopex gymnocercus, 36\% de Leopardus pardalis, $33 \%$ de Cerdocyon thous, sendo estas as espécies com maiores freqüências de registros. Dentre as espécies com baixos valores de freqüência de vestígios estiveram Eira barbara, em aproximadamente 6\% dos percursos, Chrysocyon brachyurus em 5\%, e Herpailurus

Tabela I. Espécies de carnívoros do Parque Nacional dos Aparados da Serra, registradas de fevereiro a dezembro de 1998 (1, visual; 2 , rastros; 3, fezes; 4, carcaça; 5, relatos; 6, vocalizações; 7, pêlos).

\begin{tabular}{|c|c|c|c|c|c|c|c|c|}
\hline \multirow[t]{2}{*}{ Família/Espécie } & \multirow[t]{2}{*}{ Nome popular } & \multicolumn{7}{|c|}{ Forma de registro } \\
\hline & & 1 & 2 & 3 & 4 & 5 & 6 & 7 \\
\hline \multicolumn{9}{|l|}{ Canidae } \\
\hline Cerdocyon thous & Graxaim-do-mato & $\mathrm{X}$ & $\mathrm{X}$ & $\mathrm{X}$ & & $\mathrm{X}$ & & \\
\hline Chrysocyon brachyurus & Lobo-guará & & & $\mathrm{X}$ & & $\mathrm{X}$ & & $\mathrm{X}$ \\
\hline Pseudalopex gymnocercus & Graxaim-do-campo & $\mathrm{X}$ & $\mathrm{X}$ & $\mathrm{X}$ & $\mathrm{X}$ & $\mathrm{X}$ & $\mathrm{X}$ & \\
\hline $\begin{array}{l}\text { Felidae } \\
\text { Hernailurus vauarondi }\end{array}$ & Janarundi & $\mathrm{Y}$ & & & & & & \\
\hline Leopardus pardalis & Jaguatirica & & $\mathrm{X}$ & $\mathrm{X}$ & & $\mathrm{X}$ & $\mathrm{X}$ & \\
\hline Leopardus sp. & Gato-do-mato & $\mathrm{X}$ & $\mathrm{X}$ & & & $\mathrm{X}$ & & \\
\hline $\begin{array}{l}\text { Puma concolor } \\
\text { Mustelidae }\end{array}$ & Leão-baio & $\mathrm{X}$ & $\mathrm{X}$ & $\mathrm{X}$ & $\mathrm{X}$ & $\mathrm{X}$ & $\mathrm{X}$ & \\
\hline Conepatus chinga & Zorrilho & & $\mathrm{X}$ & & $\mathrm{X}$ & $\mathrm{X}$ & & \\
\hline Eira barbara & Irara & $\mathrm{X}$ & $\mathrm{X}$ & $\mathrm{X}$ & & $X$ & & \\
\hline Galictis cuja & Furão & $\mathrm{X}$ & $\mathrm{X}$ & $\mathrm{X}$ & & & & \\
\hline Lontra longicaudis & Lontra & $\mathrm{X}$ & $\mathrm{X}$ & $\mathrm{X}$ & & $\mathrm{X}$ & & \\
\hline Procyonidae & & & & & & & & \\
\hline Nasua nasua & Quati & $\mathrm{X}$ & $\mathrm{X}$ & $\mathrm{X}$ & & $\mathrm{X}$ & & \\
\hline Procyon cancrivorus & Mão-pelada & & $\mathrm{X}$ & $\mathrm{X}$ & $\mathrm{X}$ & $\mathrm{X}$ & & \\
\hline
\end{tabular}

Tabela II. Presença (1) ou ausência (0) das espécies de carnívoros identificados no Parque Nacional dos Aparados da Serra, durante o período de março de 1999 a março de 2000 (Q, quadrículas de 4 km x 4 km; T, total de quadrículas onde cada espécie foi registrada).

\begin{tabular}{|c|c|c|c|c|c|c|c|c|c|c|c|c|c|c|c|}
\hline Espécies & Q1 & Q2 & Q3 & Q4 & Q5 & Q6 & Q7 & Q8 & Q9 & Q10 & Q11 & Q12 & Q13 & Q14 & $\mathrm{T}$ \\
\hline Cerdocyon thous & 0 & 0 & 1 & 0 & 1 & 1 & 1 & 0 & 0 & 0 & 0 & 1 & 0 & 0 & 5 \\
\hline Chrysocyon brachyurus & 0 & 1 & 0 & 0 & 0 & 0 & 0 & 0 & 0 & 0 & 0 & 0 & 0 & 0 & 1 \\
\hline Pseudalopex gymnocercus & 1 & 1 & 1 & 1 & 1 & 1 & 1 & 1 & 1 & 1 & 0 & 0 & 0 & 0 & 10 \\
\hline Herpailurus yaguarondi & 0 & 0 & 0 & 0 & 0 & 1 & 0 & 0 & 0 & 0 & 0 & 0 & 0 & 0 & 1 \\
\hline Leopardus pardalis & 0 & 1 & 0 & 0 & 1 & 1 & 1 & 1 & 1 & 0 & 0 & 1 & 0 & 0 & 7 \\
\hline Leopardus sp. & 0 & 1 & 1 & 0 & 0 & 1 & 1 & 0 & 0 & 0 & 0 & 0 & 0 & 0 & 4 \\
\hline Puma concolor & 0 & 0 & 1 & 1 & 1 & 1 & 1 & 0 & 0 & 0 & 1 & 0 & 0 & 0 & 6 \\
\hline Conepatus chinga & 0 & 0 & 1 & 0 & 0 & 1 & 1 & 1 & 0 & 0 & 0 & 0 & 0 & 0 & 4 \\
\hline Eira barbara & 1 & 0 & 0 & 0 & 0 & 0 & 1 & 0 & 0 & 0 & 0 & 0 & 0 & 0 & 2 \\
\hline Galictis cuja & 0 & 0 & 0 & 0 & 0 & 0 & 1 & 0 & 0 & 0 & 0 & 0 & 0 & 0 & 1 \\
\hline Lontra longicaudis & 0 & 0 & 0 & 0 & 0 & 1 & 1 & 0 & 0 & 0 & 0 & 0 & 1 & 0 & 3 \\
\hline Nasua nasua & 0 & 0 & 1 & 0 & 0 & 1 & 1 & 0 & 0 & 1 & 0 & 1 & 0 & 0 & 5 \\
\hline Procyon cancrivorus & 1 & 1 & 1 & 1 & 0 & 1 & 1 & 0 & 1 & 1 & 0 & 1 & 0 & 0 & 9 \\
\hline Riqueza de espécies & 3 & 5 & 7 & 3 & 4 & 10 & 11 & 3 & 3 & 3 & 1 & 4 & 1 & 0 & 58 \\
\hline
\end{tabular}


Chrysocyon brachyurus

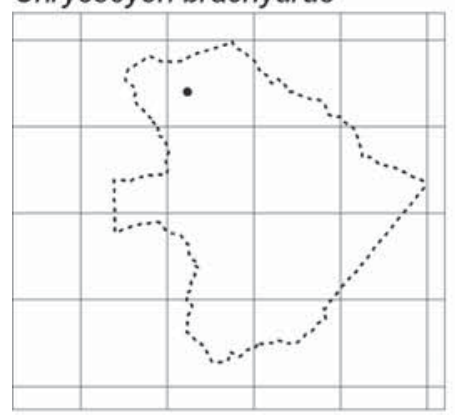

Eira barbara

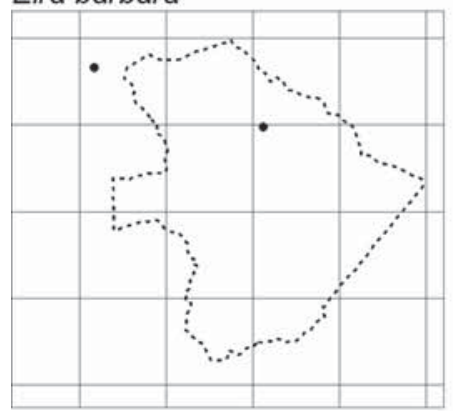

Leopardus sp.

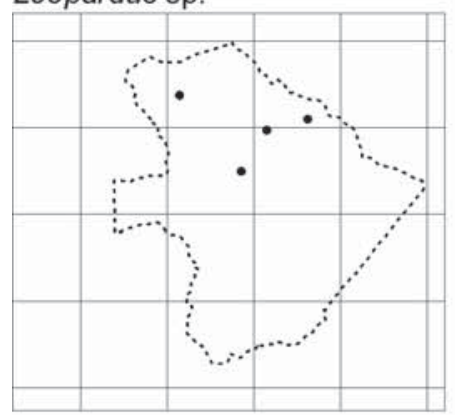

Nasua nasua

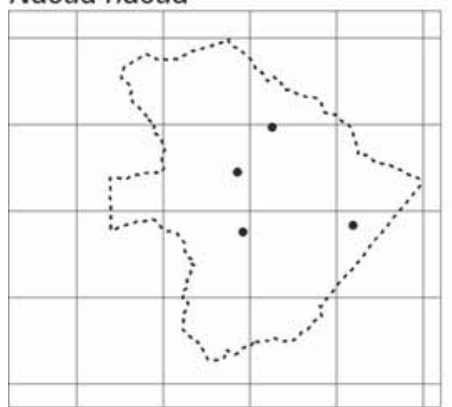

\section{Puma concolor}

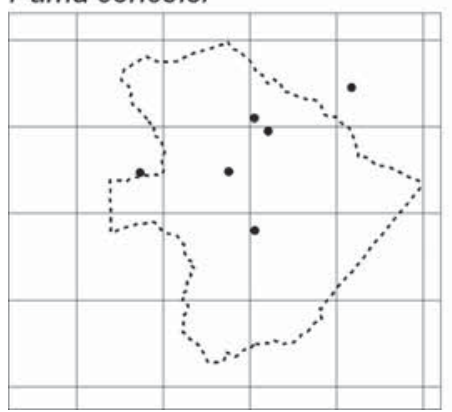

Conepatus chinga

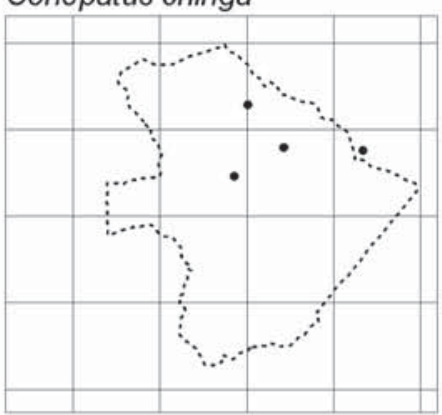

\section{Galictis cuja}

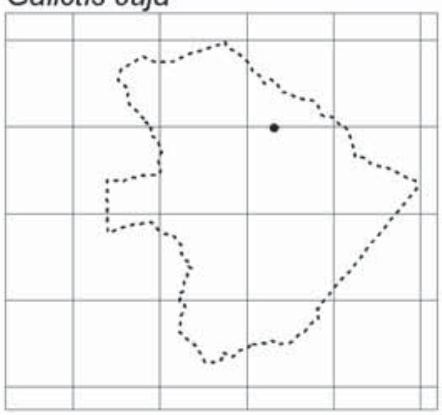

Lontra longicaudis

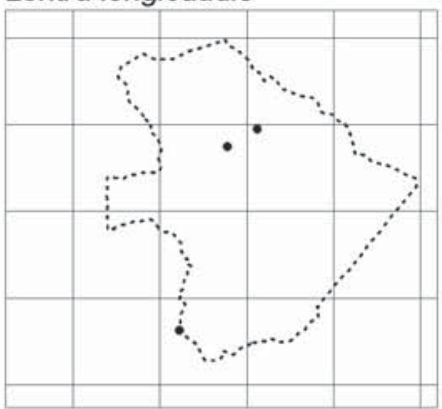

Pseudalopex gymnocercus

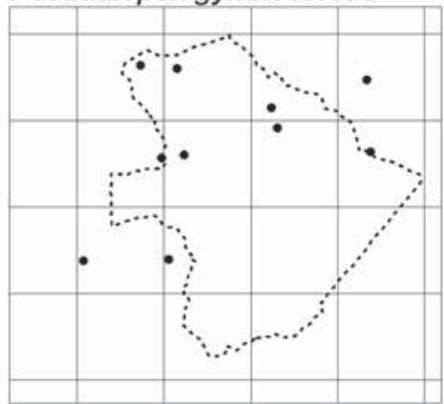

Cerdocyon thous

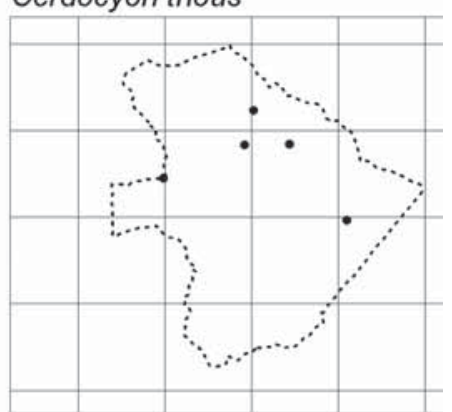

Herpailurus yagouaroundi

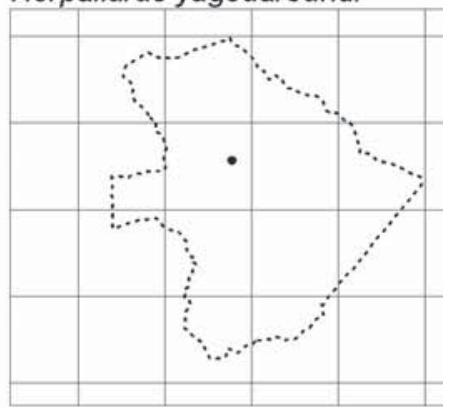

Leopardus pardalis

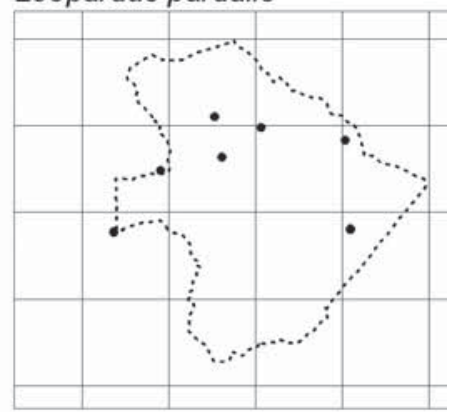

Procyon cancrivorus

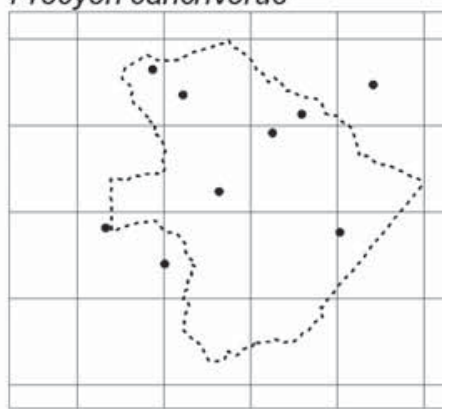

Fig. 4. Distribuição espacial dos registros de espécies de carnívoros no Parque Nacional dos Aparados da Serra em 140 transecções, de março de 1999 a março de 2000. As coordenadas geográficas estão apresentadas na figura 3.

Perímetro do Parque Nacional de Aparados da Serra

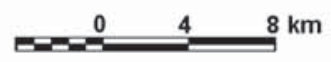

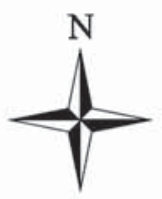


yaguarondi em 1,5\%. Em $16 \%$ dos percursos foram encontrados vestígios de Leopardus sp. e em $12 \%$ vestígios de Puma concolor. Em 11\% dos percursos registrou-se Galictis cuja e em $10 \%$ vestígios de Conepatus chinga e Lontra longicaudis.

O teste de suficiência amostral indicou que a estabilização do número de espécies registradas ocorreu em torno do oitavo percurso em cada quadrícula $(\mathrm{P}<0,01)$. Isto significa que, mesmo aumentando o número de percursos, o resultado obtido não seria significativamente diferente.

Os dados de presença/ausência das espécies de carnívoros (tab. II, fig. 4) indicaram 163 vestígios, com uma média de 0,76 vestígio por hora/pesquisador. $\mathrm{O}$ resultado da análise de agrupamento entre as unidades amostrais (fig. 5) apresenta 3 grupos considerando a riqueza de espécies de carnívoros de cada unidade amostral. Um grupo é formado pelas quadrículas 3, 6 e 7, que apresentaram a maior riqueza de espécies (de sete a

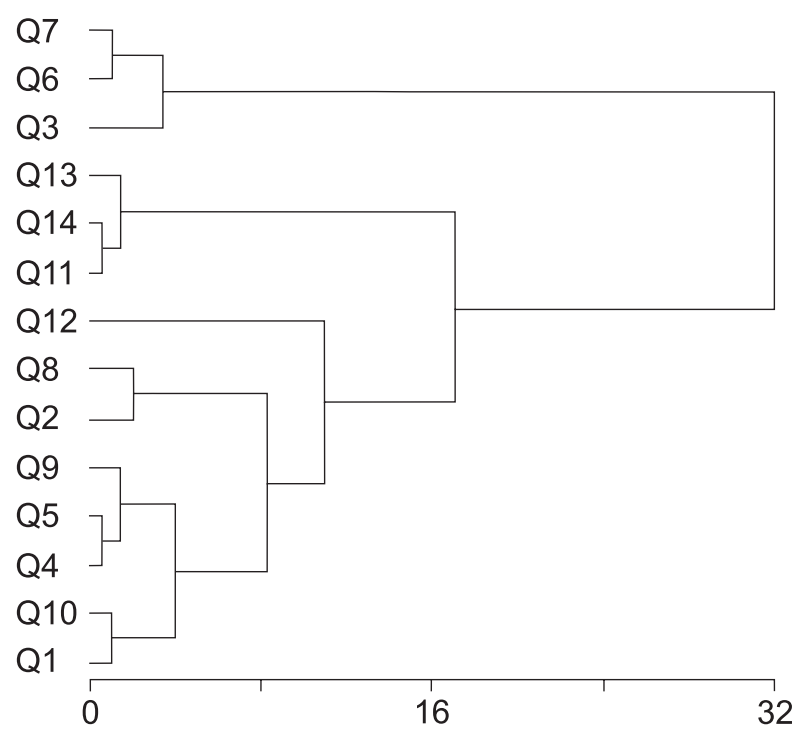

Fig. 5. Análise de agrupamento entre as unidades amostrais, com base na presença/ausência das espécies de carnívoros registradas no Parque Nacional dos Aparados da Serra, em 140 transecções, de março de 1999 a março de 2000. onze espécies). Outro grupo é formado pelas quadrículas 11, 13 e 14, com a menor riqueza (apenas uma espécie registrada). O terceiro grupo, com riqueza intermediária de espécies, é formado pelas demais quadrículas (de três a cinco espécies).

A análise de agrupamento realizada com as variáveis, ou seja, ocorrência das espécies em cada quadrícula, também gerou três grupos (fig. 6). As espécies presentes na maior parte das quadrículas (de sete a dez) foram Pseudalopex gymnocercus (pg), Procyon cancrivorus (pca) e Leopardus pardalis (lp),

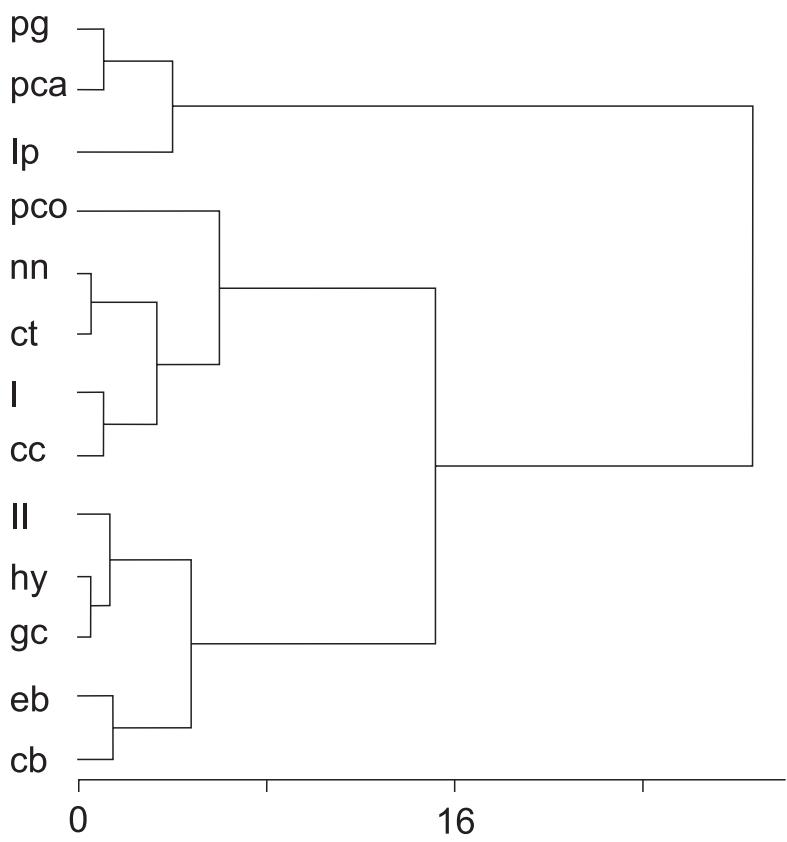

Fig. 6. Análise de agrupamento entre as espécies de carnívoros ocorrentes nas unidades amostrais no Parque Nacional dos Aparados da Serra, em 140 transecções, de março de 1999 a março de 2000. (cb, Chrysocyon brachyurus; cc, Conepatus chinga; ct, Cerdocyon thous; eb, Eira barbara; gc, Galictis cuja; hy, Herpailurus yaguarondi; 1, Leopardus sp.; 11, Lontra longicaudis; lp, Leopardus pardalis; nn, Nasua nasua; pca, Procyon cancrivorus; pco, Puma concolor; pg, Pseudalopex gymnocercus).

Tabela III. Valores das classes de cobertura do solo no Parque Nacional dos Aparados da Serra em termos percentuais (\%), conforme classificação não-supervisionada da imagem de satélite Landsat (TM) de 16 de março de 1997. Classes: 1, turfeira; 2, campo úmido/ banhado; 3, campo seco; 4, mata nebular; 5, vegetação de encosta com elementos de Mata Atlântica; 6, Mata Atlântica; 7, mata com araucária; 8, vegetação arbustiva; 9, campo alterado; 10, lavoura; 11, silvicultura; 12, solo descoberto; 13, área urbana; 14, sombra; Q, quadrículas de $4 \mathrm{~km} \times 4 \mathrm{~km}$.

\begin{tabular}{crrrrrrrrrrrrrrr}
\hline Classe & Q1 & Q2 & Q3 & Q4 & Q5 & Q6 & Q7 & Q8 & Q9 & Q10 & Q11 & Q12 & Q13 & Q14 \\
\hline 1 & 7,48 & 1,89 & 0,00 & 0,00 & 4,46 & 8,94 & 0,00 & 0,00 & 0,00 & 0,00 & 0,00 & 0,00 & 0,00 & 0,00 \\
2 & 1,69 & 10,82 & 6,25 & 10,41 & 12,66 & 9,04 & 2,00 & 5,85 & 4,20 & 1,16 & 0,21 & 0,00 & 0,08 & 0,02 \\
3 & 44,04 & 27,23 & 15,06 & 22,43 & 36,76 & 26,40 & 5,52 & 13,75 & 9,52 & 5,07 & 1,48 & 0,00 & 0,00 & 0,06 \\
4 & 0,07 & 0,05 & 0,19 & 0,48 & 0,13 & 0,71 & 3,09 & 2,05 & 1,76 & 2,22 & 0,79 & 0,00 & 0,08 & 0,00 \\
5 & 0,00 & 0,00 & 0,04 & 0,11 & 0,01 & 0,17 & 4,61 & 12,47 & 2,43 & 6,61 & 15,71 & 19,09 & 15,65 & 17,88 \\
6 & 0,00 & 0,00 & 0,00 & 0,13 & 0,14 & 0,34 & 9,95 & 14,13 & 6,06 & 17,97 & 41,35 & 56,48 & 48,79 & 67,73 \\
7 & 8,98 & 39,62 & 58,13 & 41,21 & 12,65 & 27,21 & 40,99 & 8,86 & 51,98 & 24,39 & 13,02 & 0,00 & 3,25 & 0,94 \\
8 & 32,42 & 18,75 & 18,50 & 19,68 & 30,12 & 25,61 & 11,90 & 13,02 & 17,87 & 7,22 & 2,75 & 0,00 & 0,23 & 0,23 \\
9 & 0,00 & 0,00 & 0,00 & 0,00 & 0,00 & 0,00 & 0,00 & 0,00 & 0,00 & 0,03 & 0,21 & 9,01 & 1,50 & 3,66 \\
10 & 0,00 & 0,00 & 0,00 & 0,00 & 0,00 & 0,00 & 0,00 & 0,00 & 0,00 & 0,04 & 0,10 & 0,92 & 0,38 & 0,59 \\
11 & 1,47 & 0,95 & 1,06 & 1,13 & 0,79 & 1,00 & 0,36 & 0,41 & 0,87 & 0,21 & 0,05 & 0,00 & 0,03 & 0,00 \\
12 & 3,85 & 0,69 & 0,69 & 2,88 & 2,05 & 0,00 & 0,57 & 5,10 & 0,24 & 0,03 & 0,01 & 4,68 & 0,22 & 1,04 \\
13 & 0,00 & 0,00 & 0,00 & 0,00 & 0,00 & 0,00 & 0,00 & 0,00 & 0,00 & 0,00 & 0,00 & 0,00 & 0,00 & 0,00 \\
14 & 0,00 & 0,00 & 0,08 & 1,54 & 0,21 & 0,59 & 20,99 & 24,36 & 5,07 & 35,04 & 24,30 & 9,84 & 29,80 & 7,85
\end{tabular}




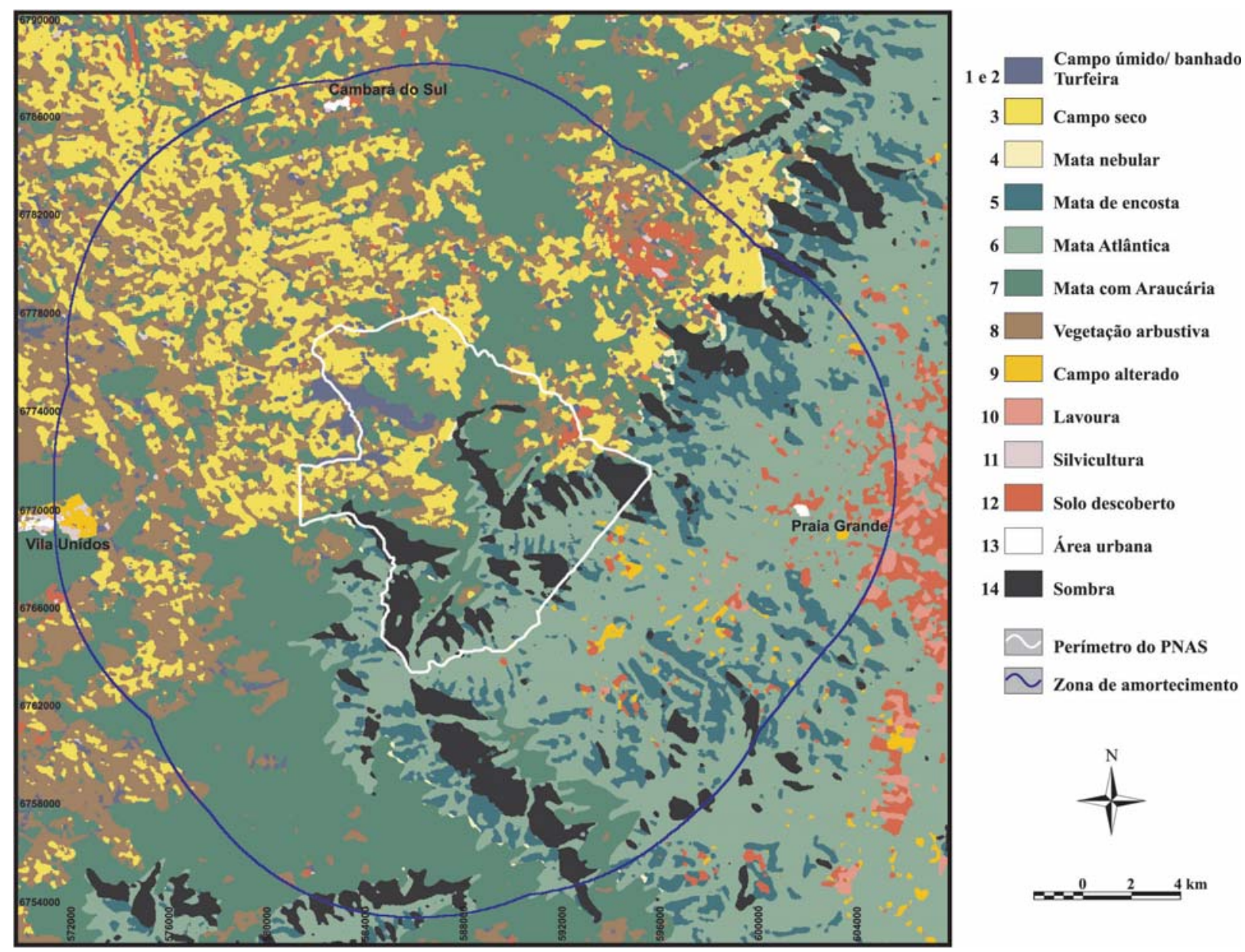

Fig. 7. Mapa de uso e cobertura do solo no Parque Nacional dos Aparados da Serra. Coordenadas geográficas em UTM, zona 22.

corroborando as informações obtidas nas transecções realizadas no período de 1998. As espécies que apresentaram uma ocorrência restrita, registradas em apenas uma ou em até três quadrículas, formaram o segundo grupo: Lontra longicaudis (11), Galictis cuja (gc), Eira barbara (eb), Chrysocyon brachyurus (cb) e Herpailurus yaguarondi (hy). As demais espécies, Puma concolor (pco), Nasua nasua (nn), Cerdocyon thous (ct), Leopardus sp. (1), Conepatus chinga (cc), formaram o terceiro grupo e apresentaram uma ocorrência intermediária (de quatro a seis quadrículas registradas).

Foram identificadas 14 classes de cobertura do solo (fig. 7, tab. III), com valores percentuais de cobertura para cada uma das unidades amostrais (quadrículas). Pode-se distinguir oito hábitats naturais (mata com araucária, mata atlântica, campo seco, campo úmido com banhado, turfeira, mata nebular, vegetação de encosta e vegetação arbustiva) e cinco alterados (silvicultura, lavoura, solo descoberto, campo alterado e área urbana). A análise de agrupamento entre as unidades revelou 4 grupos distintos (fig. 8). As quadrículas 11, 12, 13 e 14 corresponderam às áreas de encosta/planície litorânea, com grande cobertura de Mata Atlântica e vegetação de encosta. As quadrículas 8 e 10 compreenderam as bordas dos cânions. As quadrículas 1 e 5 apresentaram grandes áreas de campos e vegetação arbustiva. As demais unidades apresentaram elevada cobertura de mata com araucária, formando o quarto grupo, compreendendo as áreas do planalto.

O teste de correlação de Mantel apresentou valor positivo igual a 0,076 $(\mathrm{P}<0,05)$, indicando uma associação

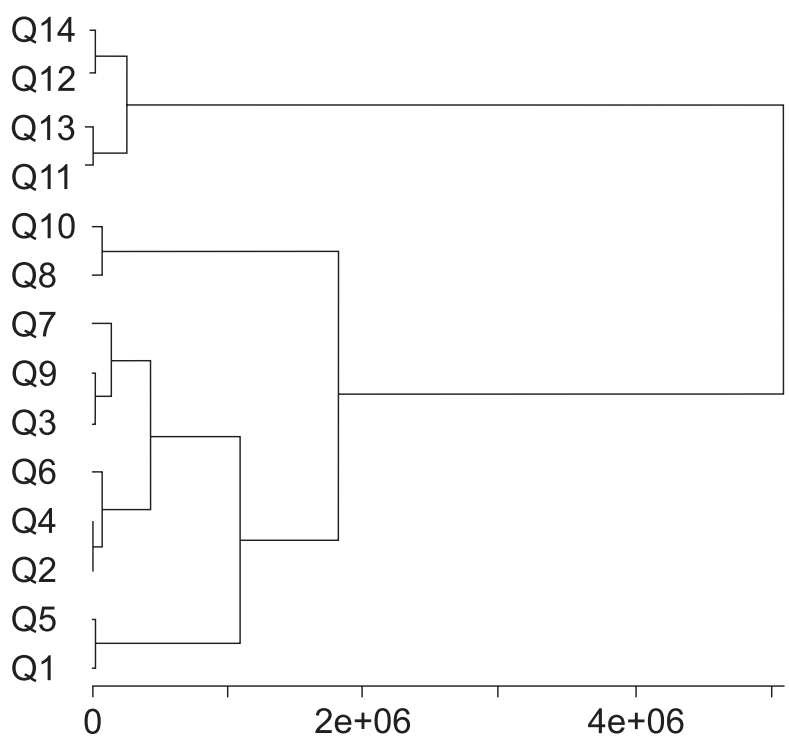

Fig. 8. Dendograma de agrupamento das unidades amostrais a partir das classes de cobertura do solo no Parque Nacional dos Aparados da Serra (imagem de 16 de março de 1997). 
significativa entre a composição de espécies e a cobertura do solo. O comportamento da correlação (fig. 9) em relação às variáveis ambientais, mostrou que as classes de cobertura, como turfeira, mata nebular, silvicultura, área urbana e solo descoberto, foram as que mais contribuíram para explicar a riqueza de espécies nas diferentes unidades amostrais.

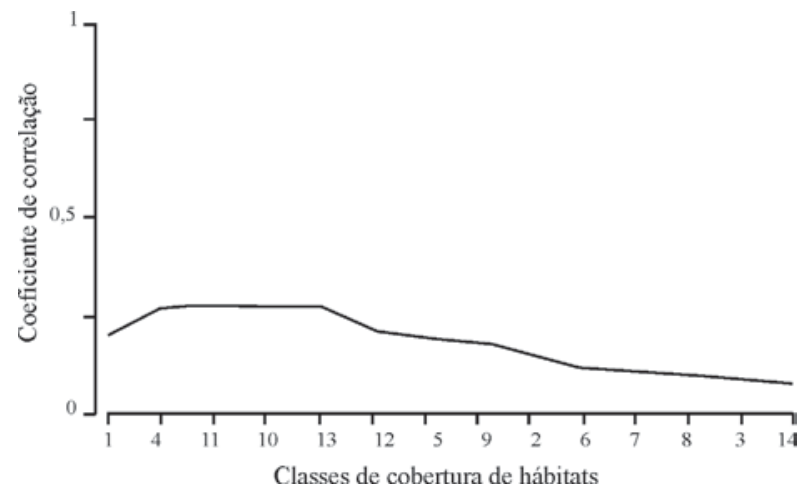

Fig. 9. Comportamento gráfico dos valores de correlação do teste de Mantel, utilizando as variáveis de hábitat de forma cumulativa.

\section{DISCUSSÃO}

A composição dos carnívoros do Parque Nacional dos Aparados da Serra está de acordo com as distribuições geográficas propostas por SiLVA (1994), EMmons \& Feer (1997) e EIsenberg \& RedFord (1999). Para o gênero Leopardus, cuja espécie não foi possível a confirmação por pegadas, salienta-se que provavelmente a espécie envolvida seja Leopardus wiedii ou Leopardus tigrinus, isso em função do seu tamanho corpóreo e da distribuição geográfica potencial apresentada por Oliveira (1994). Outras espécies não registradas na área de estudo foram onça-pintada, Panthera onca (Linnaeus, 1758), extinta na região, e gato-do-mato-grande, Oncifelis geoffroyi (Orbigny \& Gervais, 1843).

A composição registrada pode estar subestimada, mesmo tendo-se identificado a maioria das espécies de carnívoros citada para a região. Comparando as 13 espécies com as 16 registradas (IBDF, 1982), verifica-se a presença de dois mustelídeos (Galictis vittata e Conepatus semistriatus) e da inclusão dos felinos Leopardus wiedii ou Leopardus tigrinus (considerandose que Leopardus sp. seja uma destas espécies registrada). Em relação aos felinos, tais diferenças talvez sejam decorrentes de não terem sido realizadas amostragens mais detalhadas nas encostas do PNAS, que apresentam cobertura de Mata Atlântica, sendo um ambiente mais relacionado a espécies mais tropicais como os gatos pequenos. Outra diferença nas duas listas seria que os mustelídeos relacionados no plano de manejo não ocorrerem na região, conforme EISENBERG \& REDFORD (1999).

A coexistência entre as espécies simpátricas de carnívoros é possível através de dois processos ecológicos fundamentais: a seleção de hábitat pelas espécies e as diferentes formas de utilização dos recursos (ZALAPA et al., 1998). Em relação à seleção de hábitat,
KREBS (1978) atribuiu esta a fatores tanto evolutivos como comportamentais. A estrutura da vegetação, alimento e elementos florísticos específicos (espécies de plantas que influenciam a distribuição de certos animais), bem como os recursos alimentares, são os fatores que mais influenciam na preferência de hábitat em carnívoros (Yarsley \& Samuel, 1980; Ceballos \& Galindo, 1984; OzAGa \& HARger, 1996; Zalapa et al., 1998).

Embora não seja muito alto o grau de associação entre as variáveis ambientais de cobertura do solo (considerado aqui como hábitats potenciais que condicionariam uma respectiva composição de fauna) e a presença/ausência de carnívoros para cada uma das quadrículas, verifica-se que os carnívoros no PNAS apresentam uma distribuição espacial associada aos hábitats dos quais se utilizam naturalmente. Os hábitats alterados podem estar influenciando a menor riqueza de espécies em algumas regiões do PNAS, visto que compreenderam as mesmas quadrículas que apresentaram maior proporção destes ambientes, embora em alguns casos apresentassem cobertura significativa de Mata Atlântica, como as quadrículas 10 e 14. As quadrículas que apresentaram maior riqueza de hábitats foram também as de maior riqueza de espécies de carnívoros, principalmente nas áreas que apresentaram mata com araucária, semelhante ao trabalho de CHEREM \& PeREZ (1996), que também registraram, em Santa Catarina, a maioria das espécies de carnívoros neste ambiente. Percebe-se também maior riqueza de espécies em estradas junto aos ambientes naturais utilizados pelos animais, devido ao fato de ser muito frequiente que estes se utilizem de trilhas e estradas para seus deslocamentos e sinalização intra-específica (DyKE et al., 1986), sendo ainda locais de fácil amostragem, pois pegadas e fezes ficam visíveis (RABINOWITZ \& WALKER, 1991).

Quadrículas com baixa riqueza de carnívoros também se caracterizaram pela maior proporção de cobertura de áreas arbustivas, turfeiras e campo seco, sendo que os carnívoros presentes nestas quadrículas são os animais com maior afinidade com estes hábitats, tais como Pseudalopex gymnocercus, Cerdocyon thous e Procyon cancrivorus (YANosky \& Mercolli, 1989; Silva, 1994; MacDonald \& Courtenay, 1996).

Menores valores de riqueza de espécies de carnívoros são encontrados também nas quadrículas que se localizam nas bordas dos cânions Itaimbezinho e Faxinalzinho, as quais apresentam grande cobertura de vegetação de encosta. Parece que a baixa riqueza de carnívoros deve-se ao fato das escarpas dos cânions consistirem em uma barreira geográfica para as espécies e pelas partes menos íngremes destas quadrículas estarem ocupadas por hábitats alterados pela ação antrópica, sendo que os animais presentes nas mesmas foram localizados no Planalto. É importante salientar ainda que, mesmo que esta interpretação seja coerente com os dados obtidos, a metodologia utilizada talvez não seja a ideal para detectar a presença de carnívoros em áreas tão íngremes, uma vez que foram realizados percursos junto às encostas destas quadrículas, nas áreas mais acessíveis.

O fato das quadrículas centrais do Parque terem apresentado maior riqueza de carnívoros, em comparação às quadrículas mais externas, pode talvez estar 
expressando o grau de proteção que estas áreas possuem, resultante das interações antrópicas do entorno. Percebeu-se também que as quadrículas centrais são áreas mais protegidas por serem de fácil acesso à fiscalização. Já as quadrículas limítrofes estariam mais à mercê das degradações, como caça, presença de gado, queimadas de campo e derrubada de mata nativa, que ocorrem próximas do Parque, junto aos seus limites.

Através de revisões de literatura foi possível o estabelecimento de relações entre o uso dos hábitats com os hábitos de vida das espécies, que podem auxiliar a explicar os resultados observados. Verificamos que a maioria das espécies registradas neste estudo são terrestres e cursoriais, como os canídeos Pseudalopex gymnocercus, Cerdocyon thous e Chrysocyon brachyurus e os mustelídeos Conepatus chinga e Galictis cuja, sendo adaptados a regiões mais planas (EISENBERG \& REDFORD, 1999).

Já os felinos Leopardus pardalis, Leopardus sp., o mustelídeo Eira barbara e o procionídeo Nasua nasua possuem hábitos escansoriais, estando adaptados à vida nas florestas (LuDLOw \& SunQuIST, 1987; KONECNY, 1989; YANOSKY \& Mercolli, 1989, 1992). As demais espécies (Herpailurus yaguarondi, Procyon cancrivorus e Lontra longicaudis) são relacionadas com cursos d'água (GugGisBerg, 1975; KoneCNy, 1989; EMMONS \& FEER, 1997; Eisenberg \& RedFord, 1999). Puma concolor configurase como uma espécie generalista no uso dos hábitats (EISENBERG \& REDFORD, 1999).

Pseudalopex gymnocercus foi registrada em um maior número de quadrículas (10), todas no Planalto; é característica de campos, podendo utilizar áreas arbustivas e bordas de florestas. Procyon cancrivorus, presente em 6 quadrículas do planalto e 3 na planície/ encosta, é um carnívoro que vive em florestas, clareiras, banhados e áreas arbustivas que estejam próximas a cursos d'água (YANOSKI \& Mercolli, 1989; Silva, 1994; EMMONs \& FEER, 1997). Ressalta-se que a região de estudo é muito rica em recursos hídricos, o que pode estar favorecendo a ocorrência desta espécie. A terceira espécie mais freqüente no PNAS é Leopardus pardalis, felino de médio porte, ameaçado de extinção (BERNARDES et al., 1990), cujo hábitat predominante são as florestas tropicais (OliveirA, 1994), registrada nas quadrículas com maior cobertura florestal (entre $27 \%$ e $50 \%$ ), sendo que seus vestígios foram detectados no interior de matas com araucária e Mata Atlântica.

Leopardus sp., presumindo-se que seja um dos pequenos felinos (Leopardus wiedii ou Leopardus tigrinus), que semelhante a Leopardus pardalis, são animais característicos de florestas (OLIVEIRA, 1994; EMMONS \& FEER, 1997), foi registrado em áreas com muita cobertura florestal e a baixa freqüência no PNAS deva-se ao fato de ser muito raro e ameaçado (OliveIRA, 1994), apresentando populações menos numerosas.

No PNAS, Cerdocyon thous foi registrada no planalto em áreas com muita cobertura florestal e de campos úmidos e, na planície/encosta, em uma quadrícula (Q12) com áreas alteradas. Essa espécie se utiliza de áreas florestadas e arbustivas (EISENBERG \& REDFORD, 1999), podendo também adaptar-se a ambientes alterados, abertos e áreas cultivadas (SUNQUist et al. 1989;
MACDonAld \& CourTnAy, 1996), estando ainda associada a cursos d'água, tendo em vista seus hábitos alimentares (YANOSKy \& Mercolli, 1989).

Nasua nasua, presente na mesma freqüência de quadrículas que Cerdocyon thous, apresenta associação com áreas de florestas (KAUFMAN, 1962), matas galerias e áreas arbustivas (EISENBERG \& REDFORD, 1999), sendo que as áreas do Parque em que ocorre também apresentam disponibilidade destes hábitats. Conepatus chinga é um pequeno carnívoro que utiliza campos, florestas secundárias, bordas de matas em recuperação e clareiras (Silva, 1994; Emmons \& FeER, 1997). No PNAS seus vestígios foram sempre encontrados nas bordas das matas das quadrículas com maior riqueza de hábitats e cobertura florestal significativa.

Puma concolor foi registrado nas quadrículas com grande riqueza de outras espécies de carnívoros (e que também são as quadrículas centrais do parque) e em áreas bem remotas, como a Q11, onde foi visualizado. É um animal territorial que está compartilhando sua área de vida com outros predadores, uma coexistência que pode estar se dando pela segregação alimentar espacial e temporal (Bothma et al., 1984; SARGEANT et al., 1987).

Existem ainda espécies com ocorrência bastante restrita na área do Parque. Entre estas, Lontra longicaudis, registrada nas quadrículas com cursos d'água significativos, como os arroios Preá, Perdizes e Faxinalzinho, é uma espécie de hábitos semi-aquáticos, utilizando lagos, rios, riachos e matas ripárias para viver (SILVA, 1994; EISENBERG \& REDFORD, 1999), sendo coerente sua presença nas áreas citadas. Embora Chrysocyon brachyurus tenha sido registrada em única quadrícula, verifica-se que esta espécie possui significativa disponibilidade de hábitats para viver, como campos naturais e vegetação arbustiva em grande concentração (Dietz, 1984; Eisenberg \& RedFord, 1999). Além de se encontrar no limite sul de distribuição da espécie, o que confere a possibilidade de haver populações menos abundantes, provavelmente a pouca oferta de recursos para esta espécie no ambiente pode estar causando também esta baixa frequiência de registros (LOMBARDI \& MOTTA-Junior, 1993).

Outros carnívoros com ocorrência restrita no PNAS foram Herpailurus yaguarondi e Galictis cuja, ambos registrados em única quadrícula, e Eira barbara, presente em duas. Herpailurus yaguarondi é um pequeno felino com maior flexibilidade quanto aos tipos de hábitats onde é encontrado (NowEll \& JACKSON, 1996), utilizando bordas de banhado, campos encharcados, florestas úmidas e áreas secundárias (EMMONs \& FEER, 1997). Também está associado a ambientes abertos, capoeiras e corpos d'água. Eira barbara esteve presente em duas áreas contrastantes, uma rica em hábitats e a outra com grande proporção de áreas arbustivas e solo descoberto. Esta espécie parece estar adaptada tanto ao uso de florestas (EISENBERG \& REDFORD, 1999) quanto a áreas com vegetação arbustiva, secundárias ou modificadas, em associação a corpos d'água (KoNECNY, 1989).

Galictis cuja, por sua vez, utiliza bordas de florestas, capoeiras, áreas arbustivas, beira de banhados ou borda de matas galerias (SILVA, 1994), sendo sua ocorrência na quadrícula 7 explicada pela presença destes 
tipos de hábitats, embora sua ausência em outras áreas não seja de fácil interpretação. Para estas espécies com pequeno número de registros, pode estar acontecendo algum fator (ou fatores) que esteja impedindo a ocupação em áreas com hábitats disponíveis para estes carnívoros, além da limitação de registro das espécies imposta pelos métodos utilizados.

No Brasil, muitas espécies de mamíferos carnívoros encontram-se em estado vulnerável ou crítico em relação à conservação (FonseCA et al., 1994), sendo que atualmente a maior causa do declínio das populações destes animais é a redução ou perda de hábitats pela expansão agrícola, pecuária, exploração mineral, construção de barragens e colonização humana. Mesmo animais como o leão-baio (Puma concolor), com adaptabilidade para viver em diversos ambientes, têm atualmente suas exigências de área e alimentação como um fator limitante para sua sobrevivência, confrontandose com uso do solo para a pecuária (MAzzoli, 1993). A confirmação da presença de espécies ameaçadas (INDRUSIAK \& EIZIRIK, 2003) e de carnívoros de grande porte na área de estudo é indicadora da necessidade de realização de programas mais aprofundados de conservação para estas espécies. Os resultados obtidos mostram também diferentes formas de uso e ocupação do solo que poderão subsidiar programas de recuperação de áreas alteradas e o zoneamento da UC quando da revisão de seu plano de manejo.

Agradecimentos. Aos colegas do Laboratório de Ecologia de Vertebrados, Ezequiel Pedó, Cíntia Almeida e Igor Coelho. Ao Biólogo Gerson Buss, pelo auxílio nos trabalhos de campo. À William Wazlawik e José Luís Passos Cordeiro pelo auxílio na confecção dos mapas. Ao IBAMA, por fornecer a estrutura do PNAS para a realização deste trabalho, em especial ao Administrador Sr. Fernando Athayde Nóbrega. À PROPESQ/ UFRGS e CAPES/MEC pela concessão de bolsa de estudo aos primeiros autores.

\section{REFERÊNCIAS BIBLIOGRÁFICAS}

Becker, M. \& Dalponte, J. C. 1991. Rastros de mamíferos silvestres brasileiros: um guia de campo. Brasília, Universidade de Brasília. 180p.

Bernardes, A. T.; Machado, A. B. M. \& Rylands, A. B. 1990 Fauna brasileira ameaçada de extinção. Belo Horizonte, Fundação Biodiversitas. 62p.

Bothma, J. P.; Nel, J. A. \& MacDonald, A. 1984. Food niche separation between four sympatric Namib desert carnivores. Journal of Zoology, London, 202:327-340.

Ceballos, G. \& Galindo, C. L. 1984. Mamiferos silvestres de la cuenca de México. Cidade do México, Limusa. 229p.

Cherem, J. J. \& Perez, D. M. 1996. Mamíferos terrestres de floresta de araucária no município de Três Barras, Santa Catarina, Brasil. Biotemas, Florianópolis, 9(2):29-46.

Dietz, J. M. 1984. Ecology and social organization of the maned wolf (Chrysocyon brachyurus). Smithsonian Contributions of Zoology, Washington, 392:1-51.

Dyke, F. G. V.; Brocke, R. H. \& Shaw, H. G. 1986. Use of road track counts as indices of mountain lion presence. Journal of Wildlife Management, Bethesda, 50(1):102-109.

Eastman, J. R. 1999. Idrisi for Windows v.2.0. User's guide. Worcester, Clark University. 235p.

EISEnBerG, J. F. \& RedFord, K. H. 1999. Mammals of the neotropics, the central neotropics. Chicago, University of Chicago. v. 3, 609p.

Emmons, L. \& FeER, F. 1997. Neotropical rainforest mammals: a field guide. Chicago, University of Chicago. $307 \mathrm{p}$.
Fonseca, G. A.; Rylands, A. B. et al. 1994. Livro vermelho dos mamíferos brasileiros ameaçados de extinção. Belo Horizonte, Fundação Biodiversitas. 459p.

Guadagnin, D. L.; Sobral, M. \& Becker, F. G. 1998. A biodiversidade da região do Planalto das Araucárias no Rio Grande do Sul: importância, ameaças e recomendações. In: Richter, M. org. Conservação da biodiversidade $\boldsymbol{\&}$ desenvolvimento sustentável de São Francisco de Paula. Um plano preliminar. Porto Alegre, EDIPUCRS. $106 \mathrm{p}$.

Guggisberg, C. A. W. 1975. Wild cats of the world. New York, Taplinger. 328p.

Hagan, J. E. 1998. Cartalinx: the spatial data builder user's guide. Worcester, Clark University. 254p.

IBDF (Instituto Brasileiro de Desenvolvimento Florestal) 1982. Plano de Manejo - Parque Nacional dos Aparados da Serra. Brasília, DPNRE. 120p

IBGE (Instituto Brasileiro de Geografia e Estatística). 1986. Folha SH. 22 Porto Alegre e parte das Folhas SH. 21 Uruguaiana e SI. 22 Lagoa Mirim: geologia, geomorfologia ... Rio de Janeiro, IBGE. 796p. (Levantamento de Recursos Naturais, 33).

Indrusiak, C. \& Eizirik, E. 2003. Carnívoros. In: Fontana, C. S.; Bencke, G. A. \& Reis, R. E. orgs. Livro vermelho da fauna ameaçada de extinção no Rio Grande do Sul. Porto Alegre, EDIPUCRS, 632p.

INMET (Instituto Nacional de Meteorologia). 1992. Normais climatológicas (1961-1990). Brasil, Ministério da Agricultura e Reforma Agrária, Brasília. Departamento de Meteorologia. $84 \mathrm{p}$

Kaufmann, J. 1962. Ecology and social behaviour of the coati, Nasua narica, on Barro Colorado Island Panama. University of California Publishings of Zoology, Los Angeles, 60(3):95-222.

KoneCNy, M. J. 1989. Movement patterns and food habits of four sympatric carnivore species in Belize, Central America. In: Redford, K. \& Eisenberg, J. F. eds. Advances in neotropical mammalogy. Gainesville, The Sandhill Crane. 614p.

KreBS, C. J. 1978. Ecology: the experimental analysis of distribution and abundance. New York, Harper \& Row. 678p.

Lindzey, F. G.; Van Sickle, W. D. et al. 1994. Cougar population dynamics in southern Utah. Journal of Wildlife Management, Bethesda, 58(4):619-624.

Lombardi, J. A. \& Motta-Junior, J. C. 1993. Seed dispersal of Solanum lycocarpum St. Hil. (Solanaceae) by maned wolf, Chrysocyon brachyurus (1liger) (Mammalia, Canidae). Ciência e Cultura, Rio de Janeiro, 45(2):126-127.

Ludlow, M. E. \& Sunquist, M. E. 1987. Ecology and behaviour of ocelots in Venezuela. National Geographic Research, Washington, 3(4):447-461

MacDonald, D. W. \& Courtenay, O. 1996. Enduring social relationships in a population of crab-eating zorro, Cerdocyon thous, in Amazonian Brazil. Journal of Zoology, London, 239:329-355.

MANLY, B. F. J. 1994. Multivariate statistical methods: a primer. London, Chapman \& Hall. 215p.

Marcuzzo, S.; Pagel, S. M. \& Chiappetti, M. I. S. 1998. A Reserva da Biosfera da Mata Atlântica no Rio Grande do Sul. Reserva da Biosfera da Mata Atlântica. MAB. UNESCO. São Paulo, 11:5-60

Mazzoli, M. 1993. Ocorrência de Puma concolor (Linneus Felidae, Carnivora) em áreas de vegetação remascentes de Santa Catarina, Brasil. Revista Brasileira de Zoologia, Curitiba, 10(4):581-587.

Nowell, K. \& JACKSON, P. 1996. Wild cats: status survey and conservation action plan. Gland, IUCN/SSP Cat Specialist Group. 382p.

Oliveira, T. G. 1994. Neotropical cats: Ecology and conservation. São Luís, EDUFMA. 220p.

Ozaga, J. \& Harger, J. 1996. Winter activities and feeeding habits of northern Michigan coyotes. Journal of Wildlife Management, Bethesda, 30(4):809-818.

Pillar, V. DE P. 1997. Multivariate exploratory analysis and 
randomization testing with Multiv. Coenoses, Gorizia, 12(2-3): $145-148$.

1998. Sampling sufficiency in ecological surveys. Abstracta Botanica, Budapest, 22:37-48.

Rabinowitz, A. R. \& Walker, S. R. 1991. The carnivore community in dry tropical forest mosaic in Huai Kha Khaeng Wildlife Sanctuary, Thailand. Journal of Tropical Ecology, Cambridge, 7:37-47.

Rамво, B. 1956. A fisionomia do Rio Grande do Sul. Porto Alegre, Selbach. 443p.

Rudran, R.; Kunz, T. H. et al. 1996. Observational techniques for nonvolant mammals. In: Wilson, D.; Cole, F. et al. eds. Measuring and monitoring Biological Diversity. Standard Methods for Mammals. Washington, Smithsonian Institution. 405p.

Sargeant, A. B.; Allen, S. \& Hastings, J. O. 1987. Spatial relations between sympatric coyotes and red foxes in north Dakota. Journal of Wildlife Management, Bethesda, 51:285-293.

Silva, F. 1994. Mamíferos silvestres - Rio Grande do Sul. Porto Alegre, Fundação Zoobotânica do Rio Grande do Sul. 246p.

Simonetti, J. A. \& Huareco, I. 1999. Uso de huellas para estimar diversidade y abundancia relativa de los mamíferos de la Reserva da la Biósfera - Estación Biológica del Beni, Bolivia. Mastologia Neotropical, Mendoza, 6(1):139144.

Smallwood, K. S. \& Fitzhugh, E. L. 1995. A track count for estimating moutain lion Felis concolor californica population trend. Biological Conservation, Barkin, 71:251-259.
Soulé, M. E. \& Terborgh, J. 1999. Protecting nature at regional and continental scales: a conservation biology program for the new millenium. Bioscience, Washington, 49:809-817.

Sunquist, M. E.; Sunquist, F. \& Danake, D. E. 1989. Ecological separation in a Venezuelan Llanos carnivore community. In: Redford, K. \& Eisenberg, J. F. eds. Advances in neotropical mammalogy. Gainesville, The Sandhill Crane. 614p.

Terborgh, J. 1992. Maintenance of diversity in tropical forests. Biotropica, Lawrence, 24:283-292.

Terborgh, J.; Estes, J. et al. 1999. Role of top carnivores in regulating terrestrial ecossystems. In: Soulé, M. E. \& Terborgh, J. eds. Continental conservation: scientific foundations for regional conservation networks. Washington, Island. 227p.

Yanosky, A. A. \& Mercolli, C. 1989. Uso del bañado por mamiferos nocturnos con especial referencia a Cerdocyon thous (Linnaeus, 1766) y Procyon cancrivorus (Cuvier, 1798). Spheniscus, Bahia Blanca, 8:21-30.

_- 1992. Preferencias de hábitat y actividad del Coatí común (Nasua nasua) en la Reserva Ecológica El Bagual (Argentina). Miscellany Zoological, Barcelona, 16:179182.

Yarsley, E. F. \& SAmuel, D. E. 1980. Use of reclaimed mines by foxes in West Virginia. Journal of Wildlife Management, Bethesda, 44(3):729-734.

Zalapa, S.; Guerrero, M. et al. 1998. Preferencia del hábitat, amplitud y translape de nicho de sitio en cinco especies de carnívoros (Mammalia: Carnivora) en la costa sur de Jalisco, México. Biotam, Victoria, 9(2-3):33-46. 